eISSN 2444-7986

DOI: https://doi.org/10.14201/orl.17699

Artículo de revisión

LA PRUEBA CALÓRICA

\title{
The caloric test
}

\author{
Paz PÉREZ-VÁZQUEZ1'; Virginia FRANCO-GUTIÉRREZ ${ }^{2}$ \\ ${ }^{1}$ Hospital Universitario de Cabueñes. Gijón. Asturias. España. ${ }^{2}$ Hospital Universitario Marqués de Valcecilla. Santander. \\ España.
}

Correspondencia: paz.perez@sespa.es

Fecha de recepción: 14 de enero de 2018

Fecha de aceptación: 15 de enero de 2018

Fecha de publicación: 18 de enero de 2018

Fecha de publicación del fascículo: 1 de septiembre de 2018

Conflicto de intereses: Los autores declaran no tener conflictos de intereses

Imágenes: Los autores declaran haber obtenido las imágenes con el permiso de los pacientes

Política de derechos y autoarchivo: se permite el autoarchivo de la versión post-print (SHERPA/RoMEO)

Licencia CC BY-NC-ND. Licencia Creative Commons Atribución-NoComercial-SinDerivar 4.0 Internacional

Universidad de Salamanca. Su comercialización está sujeta al permiso del editor

RESUMEN Introducción y objetivo: La prueba calórica es una de las pruebas funcionales vestibulares que más han sido empleadas en la clínica. Se realiza una revisión con un enfoque práctico de su metodología y de la interpretación de sus resultados. Método: revisión narrativa. Resultados y Discusión: La prueba está sujeta a ciertas limitaciones, como ser sólo indicativa de la función del conducto semicircular horizontal y no tener valores absolutos de normalidad. Esto condiciona su realización y el análisis de sus resultados, que deben ser interpretados con cautela. Para interpretar correctamenteel test es necesario descartar y corregir artefactos y errores técnicos. Conclusiones: El test calórico sigue siendo una prueba muy útil, sobre todo por su capacidad para marcar el lado patológico. Pero debe ser puesta en el contexto clínico del paciente y combinarse con el resto de las exploraciones funcionales vestibulares para poder aproximar un diagnóstico o plantear un tratamiento.

PALABRAS CLAVE Test calórico; irrigación calórica; paresia canalicular; vestibulopatía bilateral; preponderancia direccional calórica

SUMMARY

Introduction and objective: Caloric test has been the most important test of vestibular function for the last century. A practical approach, including special recommendations for a more accurate completion and interpretation of this test are proposed. Method: Narrative statement. Results and discussion: The caloric test is limited to horizontal canal function and there are not absolute normative values. Thus, the procedures for administering the caloric test and for analysing the responses should be settled with caution. For accurate interpretation of the caloric test, the validity of the results must be stablished first, ruling out artefacts and technical errors. Conclusions: Caloric test is still a sensitive test for detecting common vestibular abnormalities, mainly due to its ability to point to the pathologic labyrinth. But the information from the caloric test must be used along with history, physical examination and other test to make a diagnosis and devise management plans.

KEYWORDS caloric test, caloric irrigation, vestibular paresis, bilateral vestibulopathy, caloric directional preponderance 


\section{INTRODUCCIÓN}

La prueba calórica es una de las pruebas de función vestibular más conocidas y empleadas en la clínica otoneurológica. Conceptualmente se definiría como una prueba cuantitativa del reflejo vestíbulo-ocular que, empleando un estímulo artificial para ponerlo de manifiesto, explora cada laberinto por separado. Esta definición, prometedora, veremos que choca con múltiples limitaciones con lo que la prueba calórica, en realidad, es una prueba semicuantitativa y cualitativa de la función de los conductos semicirculares horizontales. No obstante, debe seguir considerándose una prueba muy útil, siempre y cuando se interprete convenientemente y en el contexto apropiado.

\section{MECANISMO}

La prueba calórica fue introducida por Bàràny, que así mismo explicó su mecanismo, según lo que se denominó teoría convectiva: la irrigación del conducto auditivo externo con agua o aire a una temperatura por encima o por debajo de la temperatura corporal transfiere una onda de cambio de temperatura hasta el oído interno (Figura 1). El conducto semicircular horizontal, que es el más externo, experimenta un gradiente de temperatura entre su arco y la zona opuesta, más cercana al laberinto. Esto hace que la endolinfa se expanda o contraiga (calor y frío respectivamente) creándose una diferencia de densidad con el resto de la endolinfa. Con el paciente en posición de decúbito supino y con la cabeza flexionada 30 grados (es decir, el conducto en posición vertical), se producirá una corriente ampulípeta en el caso de la irrigación con calor (provocando un nistagmo batiendo hacia el lado estimulado) o una corriente ampulífuga en el caso de la irrigación con frío (provocando un nistagmo batiendo hacia el lado no irrigado) $[1,2]$.

Una teoría alternativa introducida por Gentine es que con el cambio térmico las alteraciones de densidad no crearían una corriente endolinfática, sino que modificarían la densidad relativa de la cúpula respecto a la endolinfa, haciendo aquella sensible a la gravedad. Se suele denominar teoría de la flotabilidad $[3,4]$. De los estudios realizados en preparaciones con conductos aislados de rana, obliterándolos a diferentes niveles según el punto de aplicación de la temperatura, parece derivarse que la teoría más factible sería la de flotabilidad, en detrimento de la convectiva $[3,5,6]$.
Estas dos teorías de producción del nistagmo calórico se vieron en entredicho cuando se realizaron experimentos en el espacio, es decir, sin gravedad. En ausencia de gravedad se reproduce la estimulación calórica y las dos teorías mencionadas requieren la existencia de la fuerza de gravedad para explicarse [3]. Se desarrollaron entonces teorías basadas en una expansión/contracción no gravitatoria de la endolinfa para explicar la prueba calórica[5]. Sin embargo, un mecanismo que estas teorías no gravitatorias son incapaces de explicar es el hecho de que si se coloca el paciente en decúbito prono (es decir, con el conducto horizontal en posición vertical, pero con la cúpula en situación inferior en lugar de superior) se produce un nistagmo que es inverso al desarrollado con la prueba en supino; es decir, el calor produce un nistagmo que bate hacia el lado no irrigado y el frío un nistagmo batiendo hacia el lado irrigado (Figura 1). Estos nistagmos son menos intensos que los que se producen cuando el paciente está en supino [1].

Hoy se considera que la prueba calórica es debida mayoritariamente a mecanismos gravitatorios, con una pequeña contribución de mecanismos no gravitatorios $[1,3]$.

\section{LIMITACIONES DE LA PRUEBA CALORICA}

Del mecanismo de génesis de la respuesta calórica se deducen una serie de limitaciones:

- Lo que se estimula con la prueba calórica es el conducto semicircular horizontal, (CSH) que es el más externo. Los conductos verticales, además de más profundos, quedarían, en la posición en la que se realiza la prueba, tangenciales a la gravedad, siendo mínima su participación en la respuesta nistágmica. En ningún modo pues se estimula la totalidad del laberinto [1].

- La respuesta calórica correspondería a una estimulación del conducto horizontal a muy baja frecuencia $[1,2]$. Esto es una estimación partiendo de la base de que la respuesta calórica se desarrolla en unos 120 segundos en total (desde que se inicia, aumenta hasta el máximo y se reduce hasta desaparecer). Si equiparamos este tiempo a medio ciclo de una estimulación rotatoria, tendríamos una frecuencia calculada de $1 / 240$, o sea $0,004 \mathrm{~Hz}$. Evidentemente son estímulos que no son comparables, pero nos da una idea del tipo de respuesta que se obtiene. 
- El estímulo calórico no es calibrado [1,2]. Por tanto, no se pueden establecer valores absolutos de normalidad para las respuestas individuales de cada estimulación. Aunque conozcamos de forma exacta el estímulo que aplicamos, no es posible saber la temperatura final en el oído interno. El estímulo aplicado a través del conducto auditivo externo llegaría al oído interno por la acción conjunta de tres mecanismos: convección a través del aire del oído medio, conducción a través del hueso temporal y radiación $[7,8]$. Se desconoce la participación de cada uno de ellos en la transmisión térmica, pero explica, al menos en parte, la gran variabilidad de respuestas entre diferentes individuos, que estaría relacionada con variaciones anatómicas en disposición, densidad ósea, pneumatización, etc. $Y$, desde luego, explica por qué la existencia de alteraciones morfológicas, bien inflamatorias (perforaciones, otitis crónicas, retracciones), bien secundarias a cirugía (timpanoplastias, mastoidectomías), invalidan los resultados de las pruebas calóricas, al menos como valor absoluto $[8,9]$. Por otra parte, la vascularización del oído también influye; así, por ejemplo, una vasoconstricción, por ansiedad o dolor, puede enlentecer la transmisión del cambio térmico y también prolongar la respuesta $[1,8]$.

\section{VALORACIÓN DE LOS RESULTADOS DE LAS PRUEBAS CALÓRICAS.}

Cuando se produce una estimulación calórica se desarrolla un nistagmo horizontal que se inicia tras una latencia de 15 a 20 segundos tras comenzar la irrigación, aumenta progresivamente de velocidad para alcanzar la máxima respuesta al cabo de 60-90 segundos, para después decrecer progresivamente hasta desaparecer al cabo de 120-180 segundos (Figura 2).

Se han intentado hacer mediciones en base a todos los posibles parámetros que surgen de esta respuesta: latencia, duración de la respuesta (en eras preinformáticas), frecuencia de los nistagmos, amplitud y velocidad de la fase lenta. Desde el advenimiento de los equipos informatizados, se ha estandarizado el uso de la velocidad de la fase lenta del nistagmo, pues es la que menos variabilidad presenta entre batidas sucesivas, determinándose como resultado la velocidad máxima alcanzada de la fase lenta del nistagmo [10].
Como se ha dicho, no existen valores absolutos de normalidad para la estimulación calórica. La velocidad máxima de la fase lenta puede alcanzar valores entre 5 grados por segundo $(\% / \mathrm{s})$ y 75 $\%$, estando dentro del intervalo del $95 \%$ de confianza para los sujetos normales $[10,11]$. Por tanto, no tiene valor como medida única. Como no hay valores absolutos de normalidad para la prueba calórica, los resultados se han de dar en forma de comparación de las dos estimulaciones, caliente y fría, de un lado respecto a otro, surgiendo la prueba calórica bitérmica introducida por Fitzgerald y Hallpike, que es como se realiza en la clínica, con las conocidas fórmulas de Jongkees con las que se calculan los resultados de la prueba $[1,2]$ (Figura 3).

Veamos cómo se manejan e interpretan esos datos.

CÁlCULO DE LA ASIMETRÍA ENTRE LOS DOS CSH. PARESIA CANALICULAR.

Tendremos dos respuestas por cada oído (una ampulípeta y otra ampulífuga) y dos respuestas en cada dirección (dos con nistaqmos derechos y dos con izquierdos). Para estimar una eventual merma de función en un oído compararemos las respuestas de las dos estimulaciones de cada oído (ampulípeta más ampulífuga), mediante la fórmula de Jongkees de paresia canalicular:

$((V \max \quad \mathrm{DF}+\mathrm{Vmax} \quad \mathrm{DC})-(\mathrm{Vmax} \quad \mathrm{IF}+\mathrm{Vmax}$ IC) $) /(V \max \quad D F+V \max \quad D C+V \max \quad I F+V \max$ DC) $\times 100$

Siendo Vmax velocidad máxima de la fase lenta del nistagmo, $D$ derecho, I izquierdo, $F$ estimulación con frío y C estimulación con calor. Es decir, expresa el porcentaje que representa la diferencia entre las respuestas de cada oído respecto del total de las respuestas. Depende de los distintos autores, pero, en general, se considera patológica a partir de un $25 \%[1,2,10,12]$.

CÁlCULO de la ASIMETRÍA EN LA DIRECCIÓN DE LOS NISTAGMOS.

PREPONDERANCIA DIRECCIONAL.

La segunda cuantificación se refiere a la posible diferencia existente entre las respuestas que generan un nistagmo derecho (calor derecho y frío izquierdo) y las que generan uno izquierdo (calor izquierdo y frío derecho). 
La fórmula, denominada de preponderancia direccional, cuantifica cuánto representa la diferencia entre las velocidades de los nistagmos derechos y los izquierdos respecto a la velocidad total de las respuestas:

$\left(\left(V_{\max } \mathrm{DC}+\mathrm{V}_{\max } \quad \mathrm{IF}\right)-(\mathrm{V} \max \quad \mathrm{IC}+\mathrm{Vmax}\right.$ $\mathrm{DF})) /(\mathrm{V} \max \mathrm{DF}+\mathrm{Vmax} \mathrm{DC}+\mathrm{Vmax} \quad \mathrm{IF}+\mathrm{Vmax}$ DC) $\times 100$

Se suele considerar patológica a partir de un $28-30 \%[1,2,10,12]$.

CÁlCULO DE LA CAPACIDAD DE INHIBIR LA RESPUESTA CON FIJACIÓN. ÍNDICE DE FIJACIÓN. Una tercera medición que se realiza hace referencia a la capacidad del sistema de seguimiento de inhibir la respuesta vestibular provocada (Figura 4). Para ello, una vez culminada la respuesta se le pide al paciente que durante 10 segundos fije la mirada. Se comparan la velocidad de la fase lenta promedio de los 10 segundos previos a la fijación y de los 10 segundos de fijación y se estima qué porcentaje es capaz de inhibir le paciente:

\section{VmFix/VmNoFix $\times 100$}

Donde VmFIx es la velocidad media de la fase lenta durante los 10 segundos de fijación y VmNoFIx es la velocidad media de la fase lenta en los 10 segundos previos a la fijación [13].

En general, se considera que la fijación debe disminuir la intensidad de la respuesta al menos un $60 \%$. Por tanto, el índice debe ser menor o igual que $60[2,14]$.

La British Society of Audiology (BSA), considerando que la fijación se estudia en la fase de decremento de la respuesta, recomienda, para mayor exactitud comparar la velocidad media de los 10 segundos previos y la de los 10 segundos posteriores a la fijación, colocando en el denominador la suma de ambas y en el numerador la velocidad media con fijación multiplicada por dos [15]. Esta fórmula no suele emplearse.

\section{REALIZACIÓN DE LA PRUEBA}

\section{EL PACIENTE}

Debe realizarse previamente una otoscopia para confirmar la ausencia de alteraciones morfológicas que contraindiquen o puedan modificar los resultados (típicamente perforaciones, retracción, secuelas postotíticas) y realizar una limpieza minuciosa del conducto para permitir el paso correcto del fluido de estimulación [15].

- Posición del paciente. Como se ha explicado al definir el mecanismo de la estimulación calórica, el conducto semicircular horizontal debe estar en posición vertical. Para ello se puede disponer al paciente en decúbito supino con la cabeza flexionada 30 grados o sentado con la cabeza extendida 60 grados. Se suele utilizar la primera, por ser más confortable $[1,13,15]$.

- Actitud de los ojos y de la mirada. Debe evitarse la posibilidad de fijar la mirada, porque, como sabemos, disminuye la respuesta vestibular. La mejor forma de realizar el registro es con el paciente con los ojos abiertos en la oscuridad, pues con esta condición el coeficiente de variación de las respuestas es significativamente menor $[1,13,15,16]$. Si no fuera posible, se realizaría con gafas de Frenzel. En las épocas de la electronistagmografía se planteaba la realización de la prueba con los ojos cerrados, pero se demostró que la variabilidad de la respuesta era mayor que con los ojos abiertos sin fijación [16].

- Estado de alerta. Debe explicarse al paciente lo que se le va a realizar y lo que puede experimentar, para disminuir al máximo la ansiedad, ya que ésta puede modificar el resultado de la prueba, sobre todo de la primera irrigación. Si el paciente está distraído pueden anularse las respuestas vestibulares, al igual que ocurre en la prueba rotatoria. Es importante pues mantener la alerta del paciente, para que las respuestas vestibulares sean lo más intensas posibles $[13,15,17]$. Esto puede conseguirse mediante la realización de pequeños cálculos aritméticos, o simplemente conversando o haciéndole preguntas al paciente.

\section{MÉTODOS DE IRRIGACIÓN}

La estimulación de los oídos puede realizarse con agua o con aire. El agua puede instilarse de forma automatizada mediante dispositivos que pueden ser de circuito abierto (el agua fluye libremente hacia el conducto y se recoge a su salida con una batea, que es el sistema más usado) o de circuito cerrado (el agua entra en un balón cerrado que se adapta a la forma 
del conducto y por cuyo interior circula el agua). También puede emplearse el agua de forma artesanal por medio de baños de temperatura controlada, aunque resulta menos preciso $[1,13,15,18]$.

Existen dos tipos de irrigadores de aire, los que pueden calentar el aire y enfriarlo y los que pueden calentarlo, pero no enfriarlo (que son los más frecuentemente usados por ser los más económicos). Estos últimos no pueden proporcionar estimulaciones con temperaturas inferiores a la temperatura ambiente (no suelen conseguir temperaturas por debajo de los $\left.25^{\circ} \mathrm{C}\right)[1,13,15,18]$.

Se ha discutido en la literatura cual es la mejor forma de irrigación. Se puede decir que los tres métodos de irrigación mencionados producen aceptables respuestas calóricas con una reproductibilidad test-retest correcta [18-20]. Han de tenerse en cuenta algunas particularidades relativas al tipo de estimulador. Así, por ejemplo, cuando se emplea aire, los tiempos de irrigación y las diferencias de temperatura con respecto a la corporal han de ser mayores si se quieren obtener resultados similares a los provocados con agua [13]. De modo que con los irrigadores de aire que no enfrían, con los que no se pueden alcanzar esas diferencias de temperatura, las respuestas van a ser ligeramente menos intensas.

Dada la evaluación que se realiza de la prueba calórica, lo importante es la simetría en las estimulaciones de ambos oídos y cada laboratorio debe de conocer y considerar las particularidades de su sistema de irrigación.

Para tratar de estandarizar los métodos de irrigación, el American National Standards Institutel (ANSI) ha establecido unas recomendaciones que se exponen en la Tabla 1 [13].

Los irrigadores de circuito cerrado no adquirieron popularidad, entre otras cosas por ser de mantenimiento más complejo y por requerir consumibles (un balón por paciente), lo que encarecía la prueba. Por tanto, no se han incluido sus especificaciones en la tabla, que sí incluiría la BSA en sus recomendaciones [15].

\section{SECUENCIA DE LAS IRRIGACIONES}

Se ha especulado mucho respecto al efecto del orden en que se realizan las irrigaciones sobre el resultado final de la prueba $[1,12,19,21,22]$, e incluso se desarrollaron fórmulas con factores de corrección [23]. En realidad, el efecto del orden de la estimulación sobre el resultado dependía sobre todo de cambios en la calibración a lo largo de la prueba cuando ésta era realizada con registro electronistagmográfico, recomendándose por ello repetir la calibración entre estimulaciones [22]. Esto no ocurre con la videonistagmografía, que es el método que se emplea actualmente. Con la VNG, se ha podido comprobar que el orden de las estimulaciones no es relevante. Lo único que se recomienda, y sí es importante, es que los oídos sean irrigados en el mismo orden con cada temperatura, siendo indiferente empezar por los fríos o por los calientes. Tanto las estandarizaciones de la ANSI como de la BSA, de forma empírica, recomiendan empezar por los calientes $[13,15]$.

Si se emplea un irrigador de aire sin condensador será recomendable empezar por el aire frío, dado que la bajada de la temperatura, al ser espontánea por equilibrado con la temperatura ambiente, es muy lenta y, por tanto, se alargaría notablemente la prueba.

Tabla 1 Recomendaciones de la ANSI para los sistemas de irrigación.

\begin{tabular}{|l|l|l|}
\hline $\begin{array}{l}\text { Para conse- } \\
\text { guir respues- } \\
\text { tas equivalen- } \\
\text { tes }\end{array}$ & Irrigador de agua & Irrigador de aire \\
\hline Volumen & $250 \pm 10 \mathrm{ml}$ & $8 \pm 0,4 \mathrm{I}$ \\
\hline Tiempo & $30 \mathrm{~s}$ & $60 \mathrm{~s}$ \\
\hline $\begin{array}{l}\text { Temperatura } \\
\text { calor/frío }\end{array}$ & $\begin{array}{l}44^{\circ} \mathrm{C} / 30^{\circ} \mathrm{C} \\
\left( \pm 0,4^{\circ} \mathrm{C}\right)\end{array}$ & $\begin{array}{l}50^{\circ} \mathrm{C} / 24^{\circ} \mathrm{C} \\
\left( \pm 0,4^{\circ} \mathrm{C}\right)\end{array}$ \\
\hline
\end{tabular}

\section{LAPSO DE ESPERA ENTRE ESTIMULACIONES}

Lo que se pretende es que hayan cesado por completo los efectos de una irrigación antes de iniciar la siguiente. Por norma, la respuesta nistágmica desaparece al cabo de 3 minutos de finalizar la irrigación [1]. Otra cuestión es que el laberinto puede tardar unos 10-15 minutos en retornar a su estado previo a la irrigación $[7,8]$. De ahí la recomendación de irrigar con cada temperatura ambos oídos sucesivamente, pues se da tiempo a que se recupere la situación de cada laberinto antes de irrigarlo por segunda vez $[1,13]$. Como norma, se recomienda esperar al menos 5 minutos entre irrigaciones sucesivas $[1,13]$.

\section{EDAD MÍNIMA PARA REALIZAR LA PRUEBA CALÓRICA}

La prueba calórica requiere de la colaboración del paciente, por lo que no se recomienda rea- 
lizarla en niños menores de 6 años (con excepciones en caso de niños muy colaboradores) ni en pacientes adultos con déficits mentales [1].

\section{HALLAZGOS EN LA ESTIMULACIÓN CALÓRICA BITÉRMICA. SIGNIFICADO CLÍNICO}

\section{PRUEBA CALÓRICA NORMAL}

Se define un resultado normal en la prueba calórica bitérmica cuando las 4 estimulaciones son similares y, por tanto, con índices de hipofunción inferior al $25 \%$ y de preponderancia inferior al 28\% (Figura 5) [2,10,14]. Además, las respuestas han de tener una intensidad adecuada, cuyo mínimo se cifra en una suma total de las 4 respuestas superior a $10-12 \%$, según el tipo de irrigación $[10,14]$.

Una prueba calórica normal nos permite decir que los conductos semicirculares de ambos oídos, así como sus aferencias, no muestran una pérdida de función $[2,10,14]$.

El hecho de que una prueba calórica sea normal no nos permite asumir que los laberintos o la vía vestíbulo-ocular, globalmente considerados, funcionan correctamente, pues sólo analiza el CSH. Tampoco, en base a una prueba calórica normal, podemos afirmar que no existe patología vestibular.

\section{PARESIA CANALICULAR}

La paresia canalicular, también llamada hipofunción vestibular, hiporreflexia o hipovalencia vestibular (Figura 6) ocurre cuando las estimulaciones de un oído para las dos temperaturas son significativamente inferiores a las del oído contralateral (índice de Jongkees de hipofunción superior al 25\%) [2,11,14].

Indica la existencia de una lesión que puede afectar al CSH de dicho lado o a sus aferencias hasta las raíces de entrada del VIII par en el tronco del encéfalo. Localiza así el lado, pero no la posición específica de la lesión, pues no diferencia entre lesiones laberínticas y retrolaberínticas. Tampoco aporta información respecto a la naturaleza de la lesión $[2,11,14]$.

Teóricamente, una hipofunción calórica podría ocurrir como resultado de una respuesta hiperactiva del oído contralateral, lo que sería virtualmente indistinguible de lesiones ipsilaterales en base a los resultados de las pruebas calóricas. Sin embargo, esta situación es extremadamente rara Si existiera la sospecha de que el oído con estimulaciones más intensas pudiera ser el patológico, deberían descartarse problemas técnicos, de calibración o de realización de la prueba, y, sobre todo, alteraciones morfológicas (perforaciones, retracciones, etc.) $[14,24]$.

\section{PREPONDERANCIA DIRECCIONAL}

Existen dos tipos de preponderancia direccional:

- Preponderancia direccional debida a un desplazamiento de la línea de base (Figura 7). Es consecuencia de la existencia de un nistagmo en ausencia de fijación en la posición en la que se realiza la prueba (típicamente un nistagmo espontáneo). Las respuestas en la dirección del nistagmo previo se suman a él y se le restan cuando son en sentido contrario. Por tanto, las respuestas calóricas reales son equivalentes en ambos sentidos si se sustrae o se adiciona, respectivamente, la magnitud del nistagmo espontáneo. Este es el tipo de preponderancia direccional más frecuente $[2,11,14]$. El desplazamiento de la línea de base es frecuente en pacientes con déficits unilaterales, debido a la existencia de un nistagmo espontáneo que puede ponerse de manifiesto con los ojos abiertos en la oscuridad bastante tiempo después de producirse la lesión aguda. Esta situación se ha considerado como un signo de que la lesión no está aún compensada [14]. Por lo demás, este tipo de preponderancia direccional no tiene ningún valor localizante o específico de etiología de la lesión. Puede ocurrir como consecuencia de nistagmos espontáneos o posicionales tanto de origen periférico como central $[2,14]$.

- Preponderancia direccional por asimetría de la ganancia (Figura 8). Ocurre cuando las respuestas en un sentido son realmente mayores que las del sentido contrario, sin la existencia de un nistagmo previo. Tradicionalmente se consideraba un signo de afectación central, pero se ha comprobado que dicha afectación central sólo se demuestra en menos del $5 \%$ de los casos [25]. Se considera que esta asimetría en las ganancias es debida a un aumento de las respuestas dinámicas en el núcleo vestibular medial, que podría estar causada por una hiperactividad intermitente de las neuronas vestibulares primarias, no teniendo per se valor localizante o específico de patología alguna [26]. 
Por tanto, el valor de la preponderancia direccional, de cualquiera de los dos tipos, es marginal. Puede originarse en los laberintos, en los nervios vestibulares, en los núcleos y estructuras vestibulares centrales, así como en el sistema nervioso central y no aporta pues información localizante concreta por sí misma.

\section{HIPOFUNCIÓN BILATERAL}

Como se ha repetido sistemáticamente, no existen valores de normalidad absolutos para la prueba calórica, pudiendo encontrarse en pacientes normales respuestas de intensidad tan baja como de $5 \%$ s $[10,26]$.

Se habla de déficit bilateral cuando las respuestas están ausentes (Figura 9) o son de muy baja intensidad en ambos oídos [2,14]. La Bàràny Society, en sus criterios diagnósticos para el déficit vestibular bilateral, establece que debe sospecharse un déficit bilateral cuando la suma de las respuestas de cada oído en ambas estimulaciones calóricas (estimulando con agua según las normas ANSI) es inferior a $6 \%$ (la suma de las 4 respuestas inferior a $12 \%$ s) [27].

Con aire, debería bajarse la cifra a10\% la suma de las 4 estimulaciones $(5 \%$ la suma de las de cada oído) [20].

Cuando las respuestas son de intensidad muy baja, los parámetros de hipofunción unilateral y de preponderancia no son valorables [14].

Cuando se sospecha un déficit bilateral es recomendable realizar la prueba con agua de hielo, que como emplea un estímulo más potente y aumenta la alerta del paciente, puede provocar respuestas más intensas y poner de manifiesto que realmente existe función en los conductos semicirculares (Figura 10). La falta de respuestas con agua de hielo apoyaría la existencia de un déficit bilateral (Figura 9).

Debe descartarse siempre un problema que condicione una inadecuada transferencia térmica a los laberintos o la toma de medicación que pueda suprimir las respuestas vestibulares.

Una hipofunción bilateral debe siempre corroborarse con otros test adicionales, fundamentalmente test rotatorios y test de impulso cefálico $[2,13,14]$.

Globalmente, el hallazgo de una hipofunción calórica bilateral tiene un valor clínico moderado. Una vez comprobado que realmente hay una pérdida bilateral de función, esta puede ser debida a una lesión en los conductos semicirculares, en sus aferencias o en el SNC. Y no se puede aseverar en base sólo a una prueba calórica que los dos laberintos, con todos sus componentes, sean hipofuncionantes [2,14].

\section{DÉFICIT DE INHIBICIÓN CON LA FIJACIÓN}

El fallo en la inhibición del nistagmo calórico con la fijación (Figura 11) es indicativo de una lesión central, afectando córtex parieto-occipital, pons o cerebelo, si bien las más habituales son las lesiones cerebelosas medias (flóculo y estructuras circundantes) [2].

Debe descartarse la toma de medicación sedante vestibular como causa de un déficit de inhibición. Por otra parte, los pacientes a veces tienen problemas para realizar correctamente la fijación, bien por la intensidad de la respuesta, bien por la repercusión subjetiva de la estimulación, por lo que debe corroborarse con otras exploraciones, típicamente con los estudios oculomotores y las pruebas rotatorias, que deben ser concordantes [2].

Tabla 2: Resultados de la prueba calórica bitérmica.

\begin{tabular}{|c|c|c|}
\hline Anomalía & Localización & $\begin{array}{l}\text { Valor } \\
\text { clínico }\end{array}$ \\
\hline $\begin{array}{l}\text { Hipofunción uni- } \\
\text { lateral }\end{array}$ & $\begin{array}{l}\text { Lesión en el conducto } \\
\text { horizontal (CSH) o en } \\
\text { sus aferencias hasta las } \\
\text { raíces de entrada del VII } \\
\text { par en el tronco en el } \\
\text { lado de menor res- } \\
\text { puesta }\end{array}$ & Alto \\
\hline $\begin{array}{l}\text { Preponderancia } \\
\text { direccional por } \\
\text { desplazamiento } \\
\text { de la línea de } \\
\text { base }\end{array}$ & $\begin{array}{l}\text { Ninguna específica. Le- } \\
\text { sión vestibular periférica } \\
\text { en CSH o sus aferencias } \\
\text { de cualquier oído o cen- } \\
\text { tral }\end{array}$ & $\begin{array}{l}\text { Mode- } \\
\text { rado }\end{array}$ \\
\hline $\begin{array}{l}\text { Preponderancia } \\
\text { direccional por } \\
\text { asimetría en la } \\
\text { ganancia }\end{array}$ & $\begin{array}{l}\text { Ninguna específica. Le- } \\
\text { sión vestibular periférica } \\
\text { en CSH o sus aferencias } \\
\text { en cualquier oído o cen- } \\
\text { tra }\end{array}$ & Incierto \\
\hline $\begin{array}{l}\text { Hipofunción bi- } \\
\text { lateral }\end{array}$ & $\begin{array}{l}\text { Ninguna específica. In- } \\
\text { dica una lesión en am- } \\
\text { bos conductos horizon- } \\
\text { tales o sus aferencias o } \\
\text { una lesión central }\end{array}$ & $\begin{array}{l}\text { Mode- } \\
\text { rado }\end{array}$ \\
\hline Hiperreactividad & $\begin{array}{l}\text { Lesión central, especial- } \\
\text { mente en cerebelo }\end{array}$ & $\begin{array}{l}\text { Mode- } \\
\text { rado }\end{array}$ \\
\hline $\begin{array}{l}\text { Déficit de inhibi- } \\
\text { ción }\end{array}$ & $\begin{array}{l}\text { Lesión central, especial- } \\
\text { mente lesiones cerebe- } \\
\text { losas medias }\end{array}$ & $\begin{array}{l}\text { Mode- } \\
\text { rado }\end{array}$ \\
\hline
\end{tabular}

RESPUESTAS HIPERREACTIVAS

Las respuestas hiperreactivas con muy raras. Se habla de hiperreactividad calórica cuando las respuestas de uno o de ambos oídos están 
por encima de los límites normales, lo que suele situarse en velocidades de fase lenta superiores a $75 \%$ en cada estimulación [14]. Lo primero que debe descartarse son artefactos o errores técnicos, así como perforaciones o mastoides alteradas o intervenidas con técnicas abiertas. $Y$ en ocasiones podría ser debido a una alerta excesiva del paciente.

Una vez descartadas estas situaciones, una hiperreactividad indica una lesión central, por pérdida de la función inhibitoria del VOR sobre los núcleos vestibulares, típicamente lesiones cerebelosas. Eso significa que debe esperarse al mismo tiempo un déficit en la inhibición con la fijación de la respuesta o respuestas calóricas correspondientes [11,14] (Figura 12).

Dada su etiología, las respuestas hiperreactivas suelen suceder en los dos oídos o en los nistagmos de una dirección concreta, siendo muy raro que ocurran sólo en las respuestas de un oído, en cuyo caso hay que descartar siempre errores técnicos o anomalías anatómicas [14].

Los posibles hallazgos en la prueba calórica bitérmica y su significado clínico se resumen en la tabla 2.

\section{OTROS TESTS CALÓRICOS}

\section{TEST CALÓRICO MONOTÉRMICO}

En aras de conseguir acortar la prueba y de provocar menos molestias a los pacientes, se ha especulado y estudiado en múltiples ocasiones la posibilidad de realizar únicamente la exploración con frío o con calor [1,28,29]. Como se ha dicho repetidamente, no hay valores absolutos de normalidad para la prueba calórica, por lo que hay que recurrir a dar los resultados en base a fórmulas que comparan los valores obtenidos con las diferentes exploraciones en ambos oídos. Por otra parte, existen dos tipos de resultados de asimetría, que son la hipofunción y la preponderancia direccional. Aún suponiendo que se pudiera establecer un punto de corte de asimetría con una exploración monotérmica, no sabríamos si esa asimetría se correspondería al final con una hipofunción unilateral o con una preponderancia direccional, o ambas, resultados con significados clínicos completamente diferentes.

Por ello, la prueba monotémica únicamente puede ser útil como test de cribado, es decir, para marcar aquellos pacientes cuyos resulta- dos en la prueba monotérmica nos permitan inferir que el resultado, de completarla como bitérmica, sería normal (simétrica) [3-15].

Para realizar esta aproximación Enticott y cols[29] estimaron que, empleando aire frío, una asimetría menor del $5 \%$, en ausencia de un nistagmos espontáneo, permitía concluir con una sensibilidad del $99 \%$ que, de completarse la prueba con el aire caliente, esta sería simétrica (sin paresia y sin preponderancia). La sensibilidad realizando el estudio monotérmico con aire caliente era menor.

Por su parte, Lightfoot y cols. [28], realizaron un estudio similar, tanto con agua como con aire y concluyeron que la estimulación con calor (mejor que con frío en este caso) podría indicar una simetría en la prueba calórica completa si se cumplían estos tres criterios: asimetría en el test monotérmico inferior al $15 \%$, ausencia de nistagmo espontáneo y velocidad máxima de cada una de las dos estimulaciones con calor superior a $8 \mathrm{deg} / \mathrm{seg}$. En este estudio la sensibilidad era de un $95 \%$.

EL índice de asimetría en una prueba monotérmica se calcularía de forma similar al empleado para la bitérmica:

\section{$\left(V_{\max } \mathrm{D}-\mathrm{V} \max \mathrm{I}\right) /(\mathrm{Vmax} \mathrm{D}+\mathrm{V} \max \mathrm{I}) \times 100$}

Por tanto, con un test monotérmico se puede estimar si la prueba será simétrica. Pero tratar de ir más allá de esta conclusión de normalidad con el resultado de una prueba monotérmica conduciría a errores en más de la mitad de los pacientes y no es recomendable. Si la prueba monotérmica no cumple criterios de simetría, deben completarse las 4 exploraciones si se quiere dar un resultado fidedigno.

\section{TEST CON AGUA DE HIELO}

La exploración calórica con agua de hielo está indicada fundamentalmente cuando las respuestas con agua o aire convencionales son muy bajas, para confirmar un déficit bilateral $[15,27,30]$. Dado que el estímulo es más intenso (el agua de irrigación está a unos $4^{\circ} \mathrm{C}$ aproximadamente), la respuesta lo será también, pudiendo poner de manifiesto la existencia de función (Figura 10).

Para realizarlo se irriga cada oído alternativamente con el agua helada durante 20 segundos. O bien se llena cada conducto, alternativamente, con el agua helada (unos $2 \mathrm{ml}$ ) manteniéndola durante 20 segundos y volteando después la cabeza para extraerla. A continuación, se coloca la cabeza en posición medial para realizar el registro [1,13,15,30,31]. 
Como tal, es un test monotérmico (sólo estimula ampulífugamente). En ocasiones el test con agua de hielo, al aumentar la atención del paciente, puede poner de manifiesto un nistagmo espontáneo que no se haya visto previamente, pudiendo hacer pensar que un laberinto tiene función. Si se quiere completar con la estimulación ampulípeta (el equivalente a la estimulación caliente) se puede recurrir a realizar la prueba con el paciente en posición de prono, debiendo invertirse la dirección de los nistagmos (Figura 1). Si se produce esta inversión indicaría que existe función en las células ciliadas del conducto horizontal y que la respuesta no es sólo el resultado de la manifestación de un nistagmo espontáneo latente $[4,30]$. Como ocurre con la prueba calórica convencional, no existen valores absolutos de normalidad. El análisis de los posibles resultados de una prueba con agua de hielo sería:

La ausencia de respuestas tras estimular con agua de hielo indicaría una ausencia de función en el CSH irrigado [14,30].

Una respuesta con inversión al repetir la estimulación en decúbito prono indicaría que existe función en el CSH [14,30].

Una ausencia de inversión con la repetición de la prueba en prono nos indicaría que no hay función atribuible al conducto horizontal. Cuando esto ocurre la velocidad de los nistagmos obtenidos es generalmente baja. Si este fenómeno se da con respuestas nistágmicas de velocidad elevada, habrá que descartar algún problema de realización [14].

Un índice de asimetría en la prueba (sólo en supino) inferior al $5 \%$ nos indicaría simetría[29].

\section{CONSIDERACIONES A LA LECTURA E INTERPRETACIÓN DE LA PRUEBA CALÓRICA. ERRORES Y ARTEFACTOS.}

Los actuales equipos de VNG, informatizados, tienen unos algoritmos de detección de nistagmos muy desarrollados, pero no son infalibles ni mucho menos. Por otra parte, es muy importante conocer qué tipo de resultados está programado para dar el software del equipo y lo que significa cada dato que ofrece.

Por regla general, los modernos equipos nos ofrecen la prueba calórica presentando:

- El registro del trazo (posición/tiempo), es decir, los sucesivos nistagmos (Figura 2).
- El registro de la evolución de la velocidad de la fase lenta de los nistagmos (gráfico velocidad/ tiempo) de cada irrigación (Figura 2). Este trazo es especialmente importante para interpretar los resultados, pues suelen marcar en él la zona que se analiza. Es importante registrar toda la prueba calórica, no siendo aconsejable mantener los ojos cerrados durante la irrigación. Conocer el desarrollo de la respuesta permite detectar artefactos o situaciones especiales que pueden condicionar una interpretación incorrecta de los resultados.

- Varios tipos de representación gráfica intuitiva de los resultados. El más usado es el gráfico de Freyss, que representa en ordenadas la magnitud de las respuestas, con un eje para las del oído derecho y otro para las del izquierdo. En el sector positivo se representan los nistagmos izquierdos (fase lenta derecha, correspondiente a las estimulaciones con calor izquierdo y frío derecho) y en el negativo los correspondiente a los nistagmos derechos (calor derecho y frío izquierdo). Se trazan sendas líneas uniendo las dos respuestas con calor y las dos con frío. Si la prueba es normal estas líneas se cruzarán en torno al origen de la gráfica (Figura 5). Si hay hipofunción se desplazarán hacia la derecha o la izquierda, según el lado hipofuncionante (Figura 6). Si hay preponderancia direccional se desplazará el cruce verticalmente hacia arriba o abajo según la dirección de la preponderancia (Figuras 7 y 8 ). Los valores de la gráfica, en algunos programas, pueden corresponder a la frecuencia de los nistagmos y no a velocidad máxima de la fase lenta, lo que puede inducir a error. Otros gráficos, como el de Claussen y el de HaidStoll (Figura 13), representan los resultados en base a la frecuencia de los nistagmos y están en desuso. El gráfico de Sherer (Figura 14) tiene una estructura similar al de Freyss, pero se divide en dos, uno para la hipofunción (donde se comparan las sumas de las velocidades máximas de las respuestas de cada oído) y otro para la preponderancia (donde se comparan las sumas de las respuestas en cada dirección).

- Los datos numéricos de cada estimulación y los índices de análisis de la prueba. Los errores de interpretación de las pruebas calóricas más frecuentes surgen de leer directamente los datos numéricos que nos 
ofrece el programa informático, sin reparar en el trazado de la prueba. Es importante conocer a qué se corresponden esos datos numéricos que nos ofrece el programa informático. Aunque está comprobado que no es el parámetro adecuado, algunos equipos aún ofrecen resultados basados en la frecuencia de las respuestas o tienen ambas posibilidades (análisis de la frecuencia y de la velocidad) pero, por defecto, pueden tener activada la frecuencia. El análisis de los resultados en base a las frecuencias puede llevar a resultados erróneos (Figuras 13 y 14).

La mayoría de los equipos actuales están preparados para dar como valor la velocidad máxima de la fase lenta del nistagmo, pero pueden cuantificar sólo el nistagmo más intenso, sin promediar la culminación de la respuesta. En estos casos es más fácil que señalen esta velocidad máxima en un artefacto, como puede ser un parpadeo. Otro error frecuentemente cometido por los equipos es señalar como culminación de la velocidad el final de la irrigación, en el que la cabeza se corrige hacia el supino desde una posición ligeramente ladeada hacia el lado no irrigado. Ese giro supone la adición de un nistagmo por acción del reflejo vestíbulo ocular que se suma a la respuesta en ese momento y puede ser interpretado erróneamente por el equipo como la zona de máxima respuesta (Figura $15 \mathrm{~A}$ y $\mathrm{B}$ ).

Es pues muy importante revisar el registro, comprobar que la forma del trazo de evolución de la velocidad del nistagmo es correcta, ver si hay artefactos y comprobar que la respuesta máxima se produce en la franja de tiempo que le corresponde (es decir, en torno a los 60 segundos del inicio de la irrigación cuando ésta se realiza con agua o a los 90 cuando esta se realiza con aire). Y si lo que el equipo ha interpretado como respuesta más intensa es un artefacto hay que borrar éste o reconducir el análisis hacia la zona correspondiente (Figura 15 A y B). La mayoría de los equipos que se emplean actualmente permiten hacer estas correcciones, unos con mayor facilidad que otros.

Lo esperable es que las respuestas sean homogéneas, es decir, similares las 4 entre sí en los casos normales y similares dos a dos en los casos de hipofunción o de preponderancia. $Y$ es frecuente que las estimulaciones con calor sean ligeramente más intensas que las realizadas con frío. Pero, en ocasiones, una de las tres respuestas puede ser significativamente menor o mayor que las otras tres. Por fortuna, es excepcional que estas situaciones generen unos índices de hipofunción o de preponderancia anormales, pero pueden provocar dudas respecto a la posibilidad de algún error o de que estemos ante un resultado limítrofe.

Si una de las cuatro estimulaciones es menor significativamente respecto a las otras tres, puede pensarse que su irrigación, por algún motivo, haya sido inferior o menos efectiva. En estos casos es recomendable repetir dicha estimulación y si el resultado se mantiene, realizar la estimulación ipsilateral con la otra temperatura. De este modo se evita que una hipofunción pueda pasar desapercibida.

Es mucho más frecuente encontrar una estimulación significativamente más intensa que las otras tres (Figura 15B). Generalmente se corresponde con una estimulación caliente. $\mathrm{Si}$ es la primera estimulación que se ha realizado puede ser por un aumento de la alerta del paciente (no es raro que la primera estimulación sea ligeramente más intensa que las otras tres). Este hecho se puede comprobar repitiendo dicha irrigación. Sin embargo, con relativa frecuencia el resultado se repite y si, además, se realiza la prueba en decúbito prono se comprueba que con la temperatura contraria es con la que se tiene una respuesta significativamente mayor en ese oído. Es decir, sería la estimulación ampulípeta o ampulífuga, se produzca mediante frío o mediante calor, la que es más intensa Figura 15B). Esta situación de da en pacientes con diagnósticos clínicos muy diversos y no se ha demostrado hasta el momento que tenga valor o significación diagnóstica (Dra. Paz Pérez, comunicación personal, Septiembre 2011).

En suma, la repetición de alguna de las irrigaciones estaría indicada sólo si se considera que no son armónicas con la prueba global y que, además, podrían suponer una alteración significativa en el resultado final de la prueba. No se recomienda realizar más de 6 irrigaciones calóricas en una sesión. Si hubiera que realizar más repeticiones, se aconseja volver a realizar la prueba completa otro día [14].

\section{LA PRUEBA CALÓRICA EN OÍDOS PERFORADOS O ALTERADOS MORFOLÓGICAMENTE}

En un oído perforado, lógicamente, está contraindicada la estimulación con agua y debe 
hacerse con aire. Ahora bien, debe tenerse en cuenta que los resultados de la estimulación calórica de un oído perforado son muy limitados y, además, puede producir respuestas extemporáneas. Una de las más típicas es que al realizar la estimulación con aire caliente aparezca un nistagmo inicialmente invertido (batiendo hacia el lado no irrigado). Esto es debido a un efecto inicial de enfriamiento de la mucosa húmeda del oído medio [14]. También, debido a que el aire incide rápidamente sobre el oído medio, puede ocurrir que la latencia de la respuesta sea menor y que la velocidad de fase lenta del nistagmo sea más intensa de lo esperado, simulando un déficit contralateral [14].

Puesto que la prueba calórica se basa en la comparación de las respuestas de los dos oídos partiendo de la premisa de que las estimulaciones aplicadas en ellos son equivalentes, la realización de la prueba calórica en oídos perforados sólo sirve para conocer si existe respuesta del conducto horizontal de ese oído, pero no se puede deducir nada más respecto su función (si está disminuida o no) pues no son válidas las comparaciones con la respuesta contralateral. Lo mismo es aplicable a la estimulación de oídos con otitis crónica, intervenidos o no, y de oídos con alteraciones morfológicas de cualquier etiología [14,24].

\section{CONCLUSIONES}

En suma, podemos decir que la prueba calórica es una exploración relativamente sencilla de realizar y que aporta información clínica relevante, sobre todo en tanto en cuanto puede ayudar a identificar el lado patológico, si bien para interpretarla hay que recordar que está sujeta a ciertas limitaciones que deben ser tenidas en cuenta. No se debe pretender ir más allá de la información concreta y real que nos ofrece.

La prueba calórica, como ocurre con toda exploración vestibular funcional, debe de ser siempre puesta en el contexto clínico del paciente y del resto de las exploraciones vestibulares y en ningún modo puede concebirse como la única exploración a realizar en un paciente con patología vestibular.

\section{BIBLIOGRAFÍA}

1. Barin K. Background and Technique of caloric testing. In: N JG and S, editor. Balance Function Assessment and Management. San Diego, CA: Plural Publishing; 2008. p. 197-228.

2. Honrubia V. Evaluación vestibular cuantitativa. In: Suárez C, Gil- Carcedo LM, Medina J, Ortega P, Trinidad J, editors. Tratado de Otorrinolaringología y Cirugía de Cabeza y Cuello. San Fernando de Henares: Proyectos Médicos SL; 1999. p. 1011-55.

3. Valli P, Buizza A, Botta L, Zucca G, Ghezzi L, Valli S. Convection, buoyancy or endolymph expansion: what is the actual mechanism responsible for the caloric response of semicircular canals? J Vestib Res. 2003;12(4):155-65.

4. Wit, HP, Spoelstra AA SJ. Bárány's theory is right, but imcomplete. Acta Otolaryngol. 1990;110(1-2):1-6.

5. Takenouchi T, Suzuki M, Furuya M, Otsuka $\mathrm{K}$, Ogawa Y. Contribution of endolymphatic fluid shift to caloric response in plugged semicircular canals. ORL J Otorhinolaryngol Relat Spec. 2005;67(5):266-71.

6. Spoelstra HAA, Wit HP SH. Mechanism of caloric stimulation of the pidgeon's vestibular system. Acta Otolaryngol. 1991;481(Suppl):94

7. Pau HW, Just T, Sievert U, Wild W. Heat radiation during caloric vestibular test: thermographic demonstration in temporal bone experiments. Ann Otol Rhinol laryngol. 2001;110(11):1041-4.

8. Nishizawa S. Observations on conduction of caloric stimulation to the middle ear cavity by thermoscanning. 2002;12(3):504-8.

Laryngoscope.

9. Kondoh K, Kitahara T, Morihana T, Yamamoto K, Kubo T, Okumura S. Changes in caloric responses after temporal bone surgery with posterior tympanotomy. Auris Nasus Larynx. 2009;36(5):521-4.

10. Sills AW, Balow RW, Honrubia V. Caloric testing 2. Results in normal subjects. Ann Otol Rhinol Laryngol. 1977;86 (Suppl):7-23. 
11. Baloh RW, Sills AW, Honrubia V. Caloric testing 3. Patients with peripheral and central vestibular lesions. Ann Otol Rhinol Laryngol. 1977;86 (suppl):24-30.

12. Molina MI, Zapata C, Palma MJ, LópezEscámez JA. Valores poblacionales de referencia para videooculografía en el test de agitación cefálica y la prueba calórica bitérmica. Acta Otorrinolaringológica Española. 2006;57(1):34-40.

13. ANSI. Procedures for testing basic vestibular function. Am Natl Stand Inst. 1999;Revision of ANSI S3.45.

14. Barin K. Interpretation and usefulness of caloric testing. In: Jacobson, Gary P SN, editor. Balance Function Assessment and Management. San Diego, CA: Plural Publishing; 2008. p. 229-52.

15. British Society of Audiology. Recommended procedure The caloric test. $\mathrm{Br}$ Soc Audiol. 2010;April:1-25.

16. Baloh RW, Solingen L, Sills AW, Honrubia V. Caloric testing 1. Effect of different conditions of ocular fixation. Ann Otol Rhinol Laryngol. 1977;86 (Suppl):1-6.

17. McGovern TN, Fitzgerald JE. The effect of mental alerting on peripheral vestibular nystagmus during spontaneous, gaze (30 degrees left, 30 degrees right) and body positional (left \& right lateral lying) testing using electronystagmography (ENG). Int J Audiol. 2008;47(10):601-6.

18. Ansderson S. Caloric irrigators: air, open-loop water and closed-loop water. $\mathrm{Br} \mathrm{J}$ Audiol. 1995;29(2):117-28.

19. Maes L, Dhooge I, De Vel E, D'haenens W, Bockstael A, Vinck BM. Water irrigation versus air insufflation: A comparison of two caloric test protocols. Int $\mathrm{J}$ Audiol. 2007;46(5):263-9.

20. Zapala D, Olsholt KF, Lundy LB. A comparison of water and air caloric responses and their ability to distinguish between patients with normal and impaired ears. Ear Hear. 2008;29(4):585-600.

21. Alonso I, Chaparro P, Calvente R. Efecto de la secuencia de irrigación en los resultados de la paresia canalicular en la prueba calórica bitérmica. 2007;58(4):151-5.
22. Lightfoot GR. The origin of order effects in the results of the bi-thermal caloric test. Int $\mathrm{J}$ Audiol. 2004;43(5):276-82.

23. Furman JMR, Jacob RG. Jongkees' formula re-evaluated: order effects in response to alternate binaural bithermal caloric stimulation using closed-Loop irrigation. Acta Otolaryngol. 1993;113(1):3-10.

24. Kondoh K, Kitahara T, Morihana T, Yamamoto K, Kubo T, Okumura S. Changes in caloric responses after temporal bone surgery with posterior tympanotomy. Auris Nasus Larynx. 2009;36(5):521-4.

25. Halmagyi GM, Cremer PD, Anderson J, Murofushi T, Curthoys IS. Isolated directional preponderance of caloric nystagmus: I. Clinical significance. Am J Otol. 2000;21(4):559-67.

26. Cartwright AD, Cremer PD, Halmagyi GM, Curthoys IS. Isolated directional preponderance of caloric nystagmus: II. A neural network model. Am J Otol. 2000;21(4):568-72.

27. Strupp M, Kim J-S, Murofushi T, Straumann $D$, Jen JC, Rosengren SM, et al. Bilateral vestibulopathy: Diagnostic criteria Consensus document of the Classification Committee of the Barany Society. J Vestib Res. 2017;27(4):177-89.

28. Lightfoot G, Barker F, Belcher K, Kennedy V, Nassar G, Tweedy $F$. The derivation of optimum criteria for use in the monothermal caloric screening test. Ear Hear. 2009;30(1):54-62.

29. Enticott JC, Dowell RC, O'Leary SJ. A comparison of the monothermal and bithermal caloric tests. J Vestib Res. 2003;13(2-3):113-9.

30. Batuecas-Caletrio A, Montes-Jovellar L, Boleas-Aguirre MS, Perez-Fernandez N. The ice-water caloric test. Acta Otolaryngol. 2009;129(12):1414-9.

31. Schmäl F, Lübben B, Weiberg K, Stoll W. The minimal ice water caloric test compared with established vestibular caloric test procedures. J Vestib Res.2005;15(4):215-24. 


\section{ANEXO}
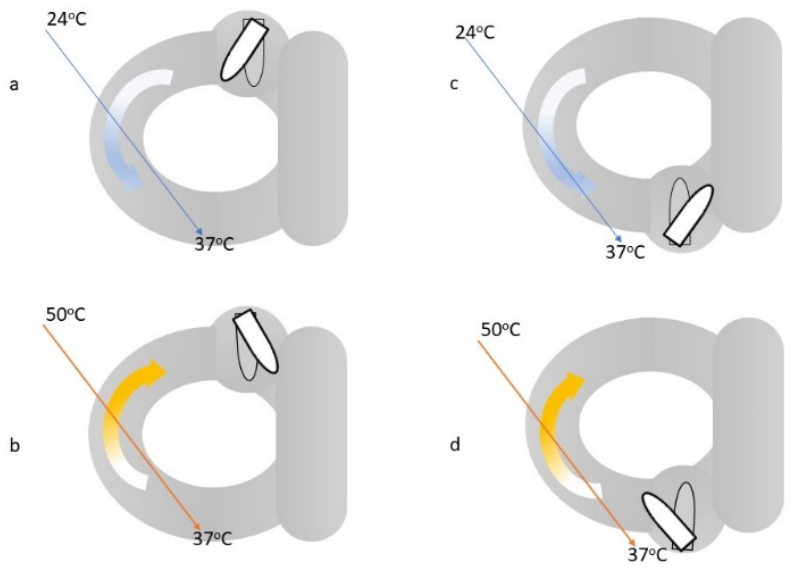

Figura 1. Esquema del mecanismo gravitatorio de producción de la respuesta calórica: a, con frío, b con calor, en la posición de decúbito supino; c con calor, d con frío, en la posición de decúbito prono.

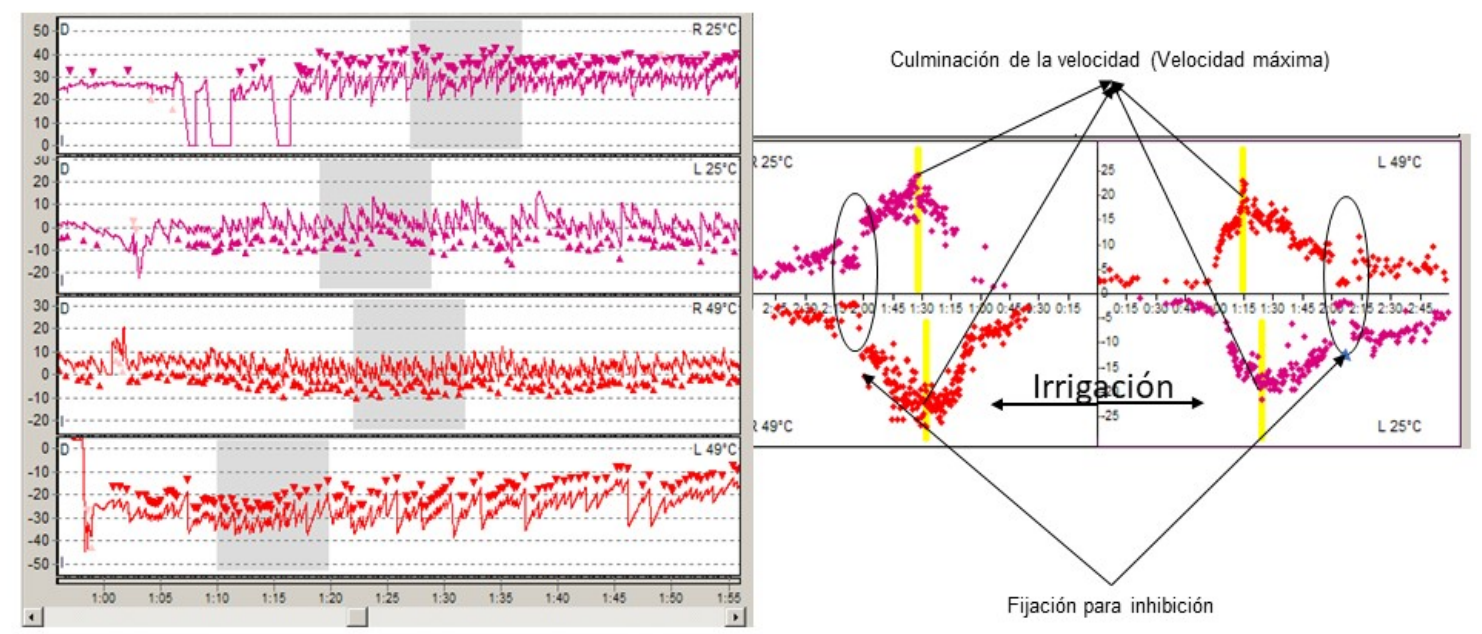

Figura 2. Desarrollo en el tiempo de las estimulaciones calóricas. A la derecha se presentan las gráficas "velocidad de fase lenta del nistagmo/tiempo" de las cuatro estimulaciones, señalando la culminación de la velocidad, con la que se hacen los cálculos, y la zona correspondiente a la inhibición. 
Índice de hipofunción

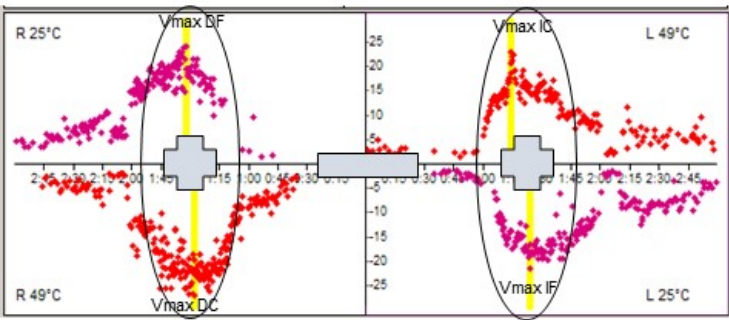

$\frac{(V \max D F+V \max D C)-(V \max I F+V \max I C)}{V \max D F+V \max D C+V \max I F+V \max D C} \times 100$

Indice de preponderancia

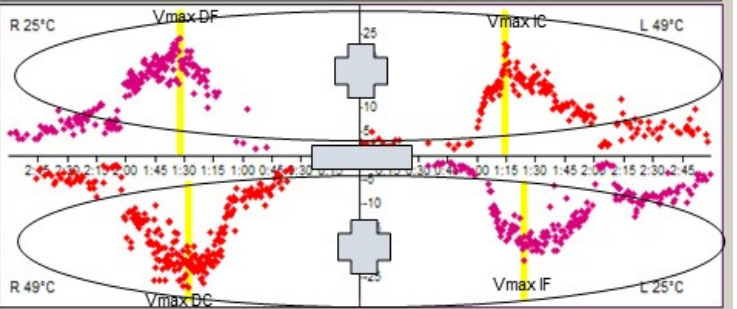

$\frac{(V \max D C+V \max I F)-(V \max I C+V \max D F)}{V \max D F+V \max D C+V \max I F+V \max D C} \times 100$

Figura 3. Cálculo de los índices de Jongkees. Vmax, velocidad máxima de la fase lenta del nistagmo; D, derecho; I, izquierdo; F, estimulación con frío; C, estimulación con calor.

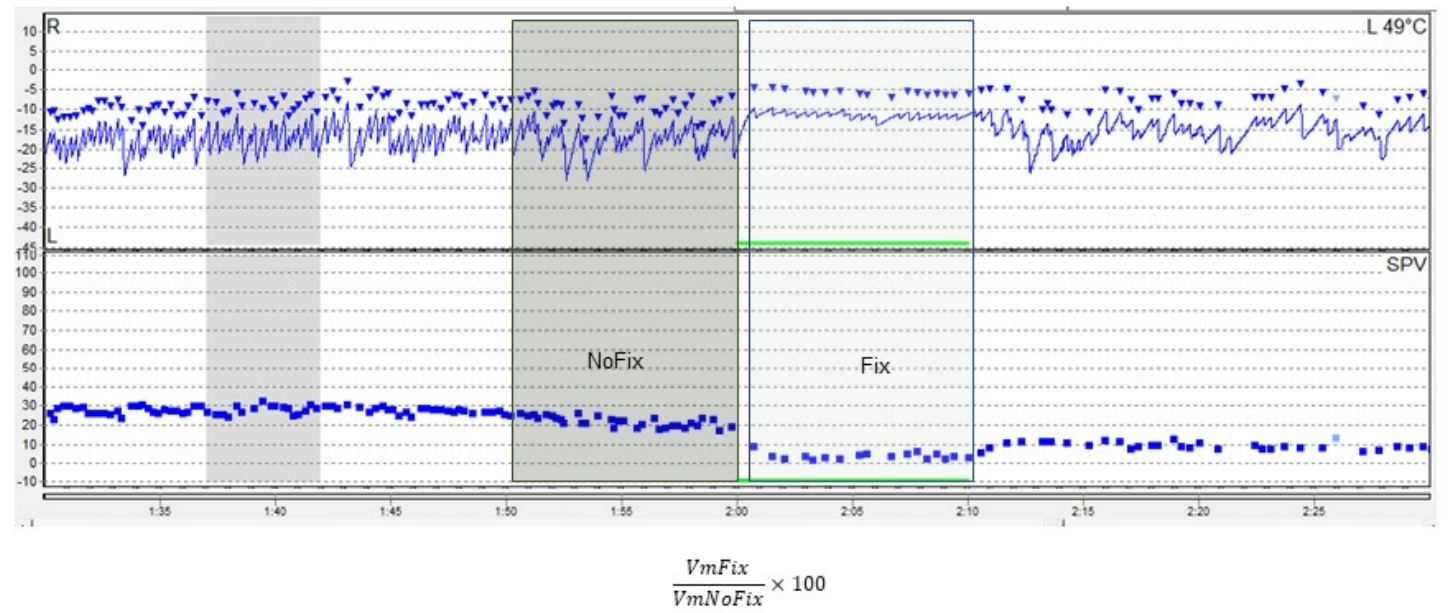

Figura 4. Cálculo del índice de fijación. VmFlx, velocidad media de la fase lenta del nistagmo durante los 10 segundos de fijación; VmNoFIx, velocidad media de la fase lenta en los 10 segundos previos a la fijación. 
LA PRUEBA CALÓRICA

PÉREZ-VÁZQUEZ P Y FRANCO-GUTIÉRREZ V
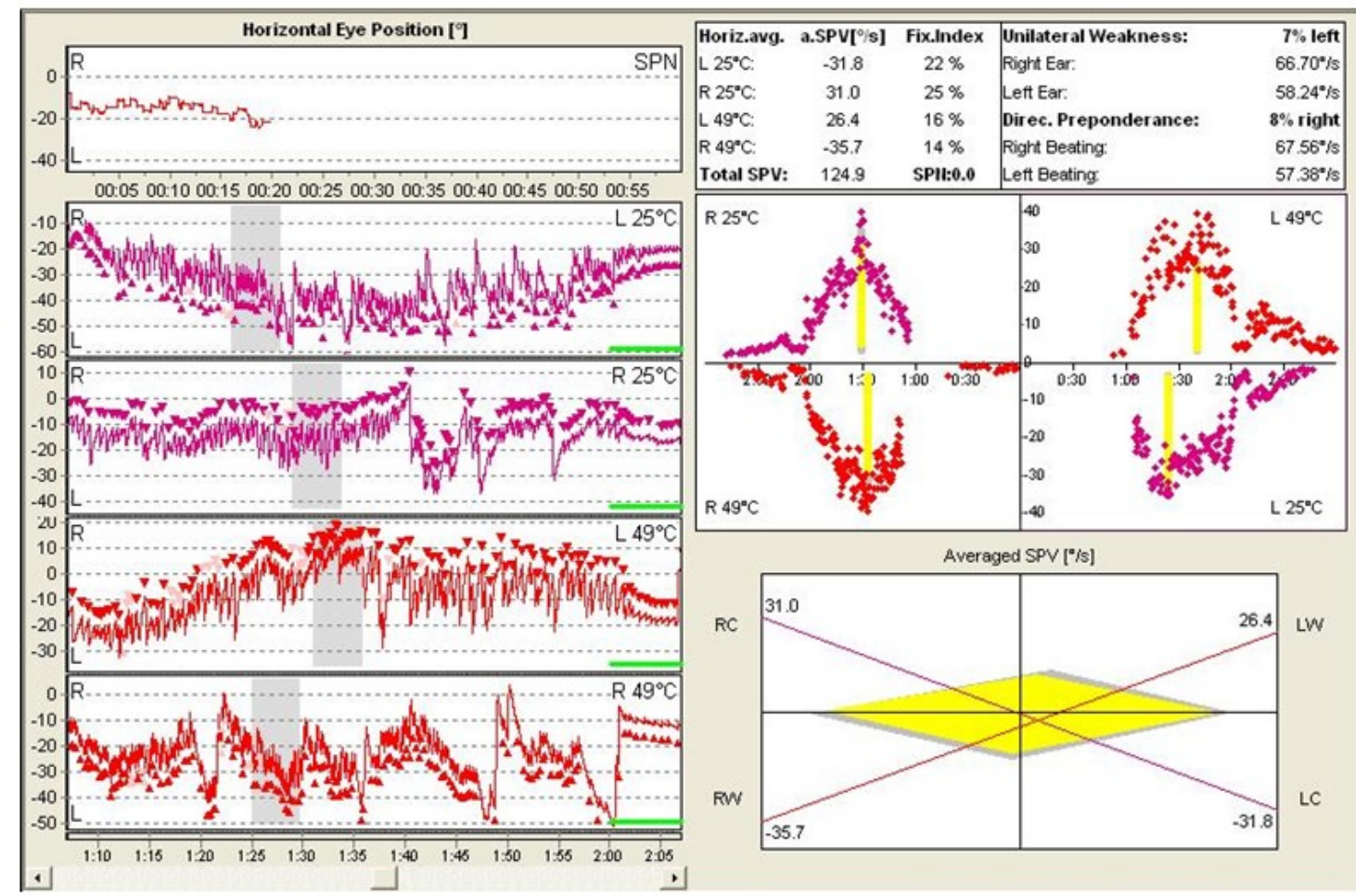

Figura 5. Prueba calórica normal.

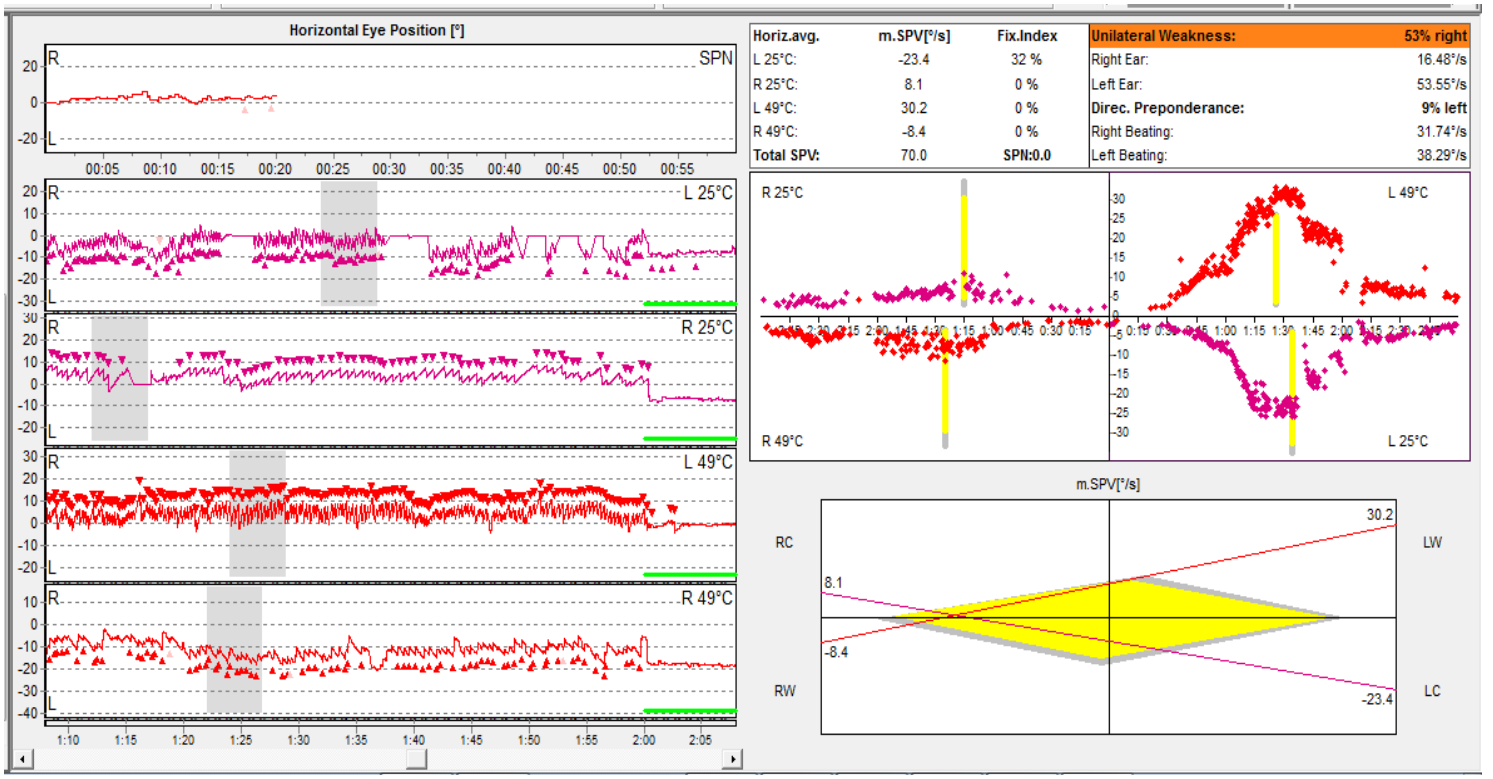

Figura 6. Paresia canalicular, derecha en el caso mostrado. 
LA PRUEBA CALÓRICA

PÉREZ-VÁZQUEZ P Y FRANCO-GUTIÉRREZ V

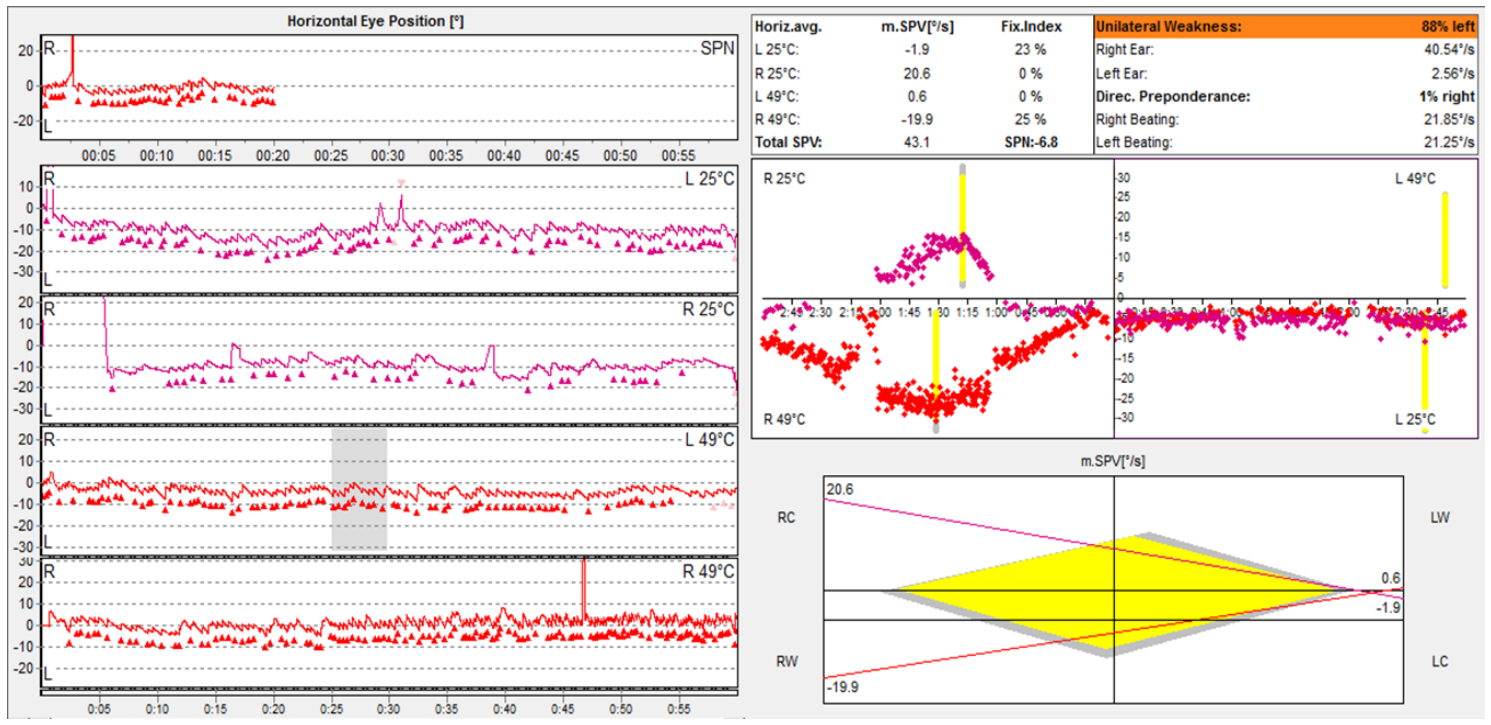

Figura 7. Preponderancia direccional por desplazamiento de la línea de base. Hipofunción izquierda en fase subaguda, con nistagmo espontáneo derecho, que desplaza la línea de base. Al ajustarse los cálculos con el nistagmo espontáneo, el índice de preponderancia es normal.
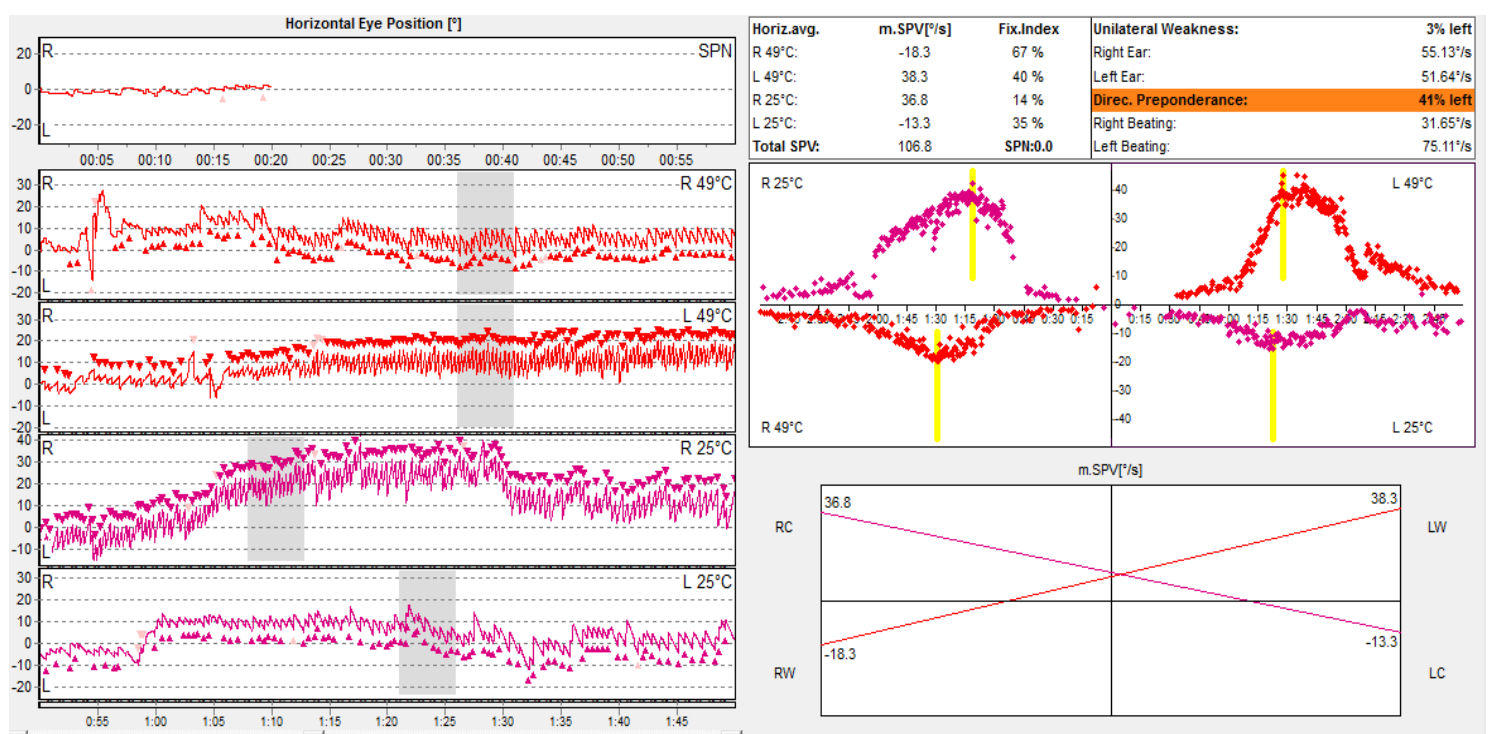

Figura 8. Preponderancia direccional por asimetría en las ganancias. 
LA PRUEBA CALÓRICA

PÉREZ-VÁZQUEZ P Y FRANCO-GUTIÉRREZ V

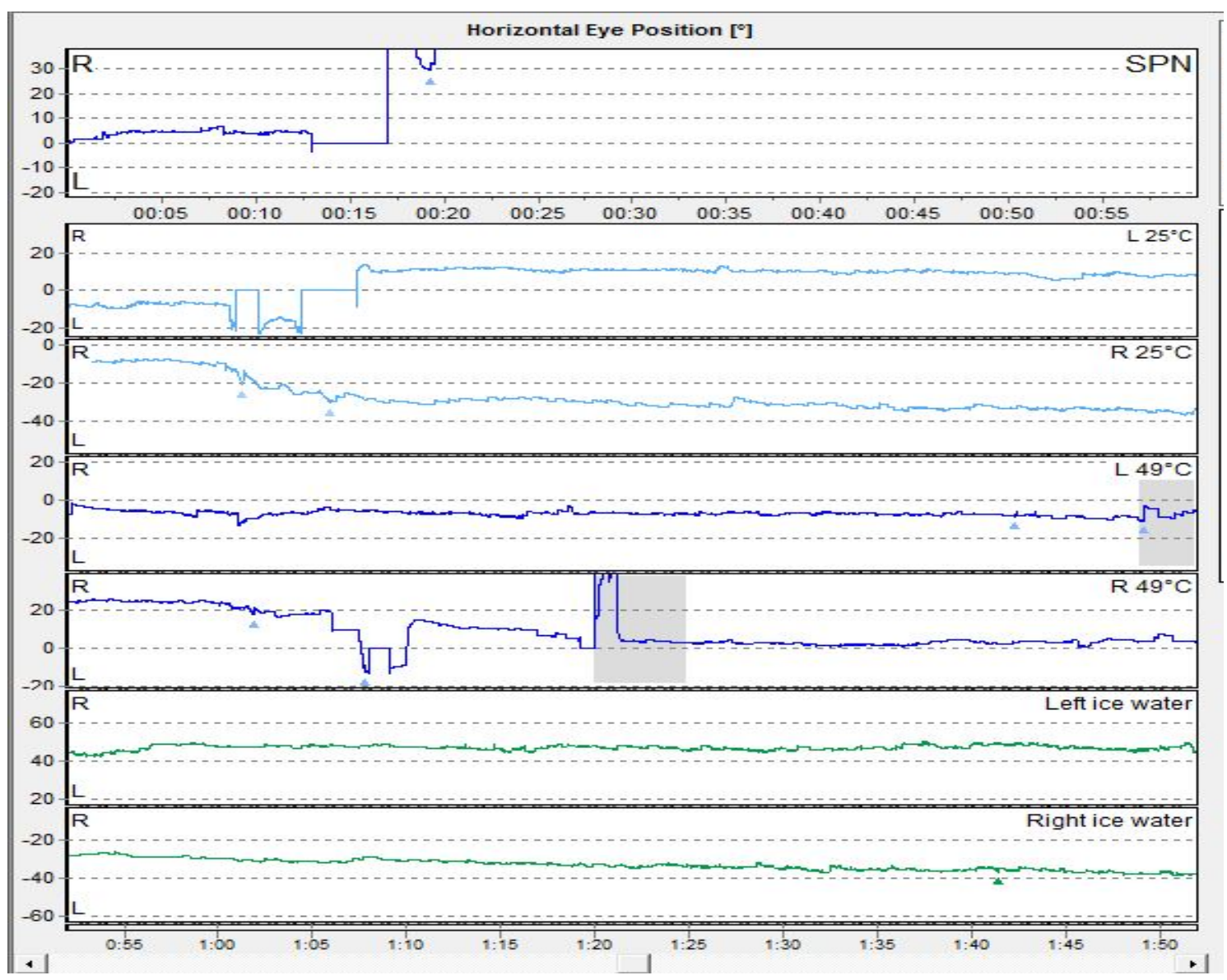

Figura 9. Ausencia de respuestas calóricas bilaterales, corroborada con agua de hielo 
LA PRUEBA CALÓRICA

PÉREZ-VÁZQUEZ P Y FRANCO-GUTIÉRREZ V
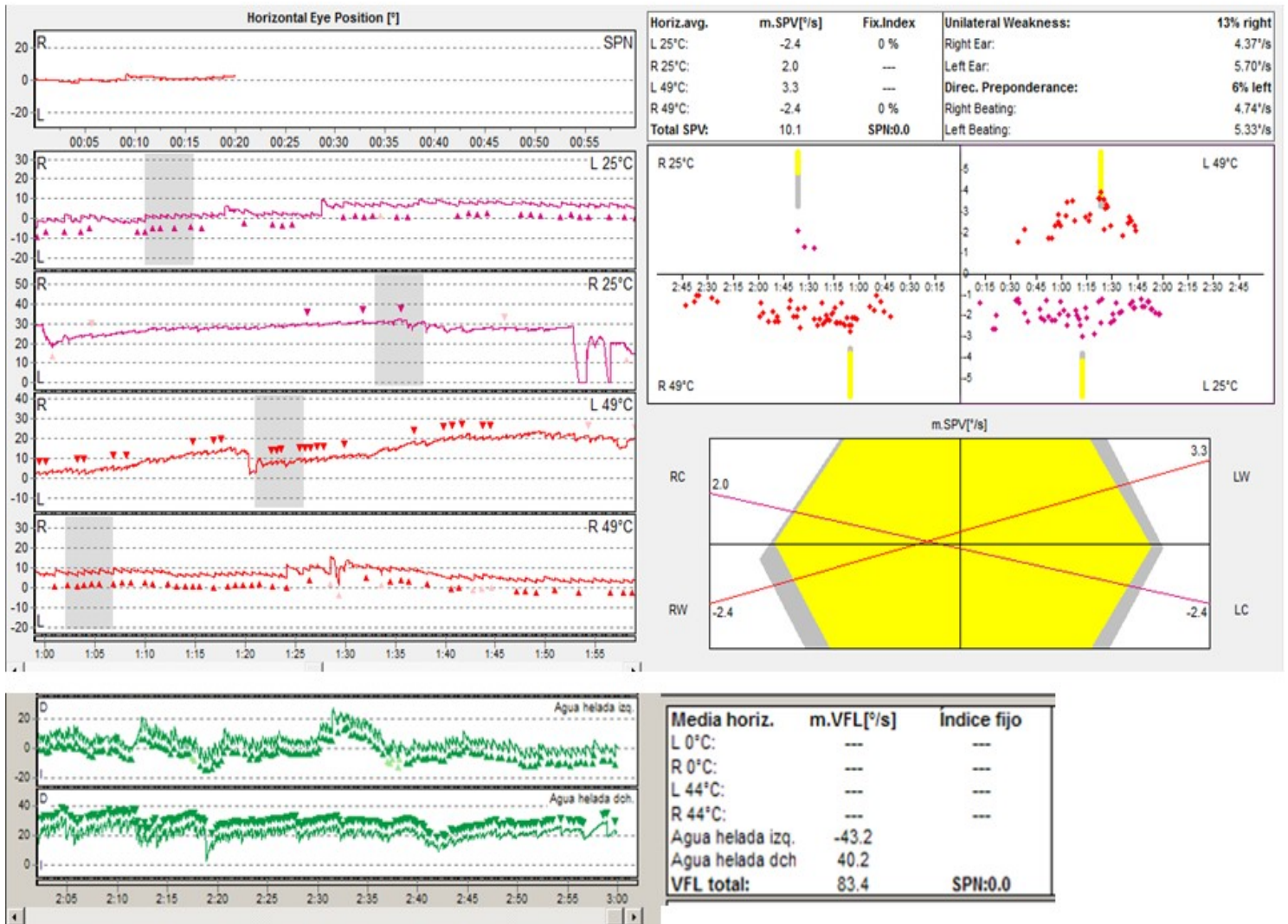

Figura 10. Déficit bilateral en la prueba calórica bitérmica, refutado con agua de hielo.
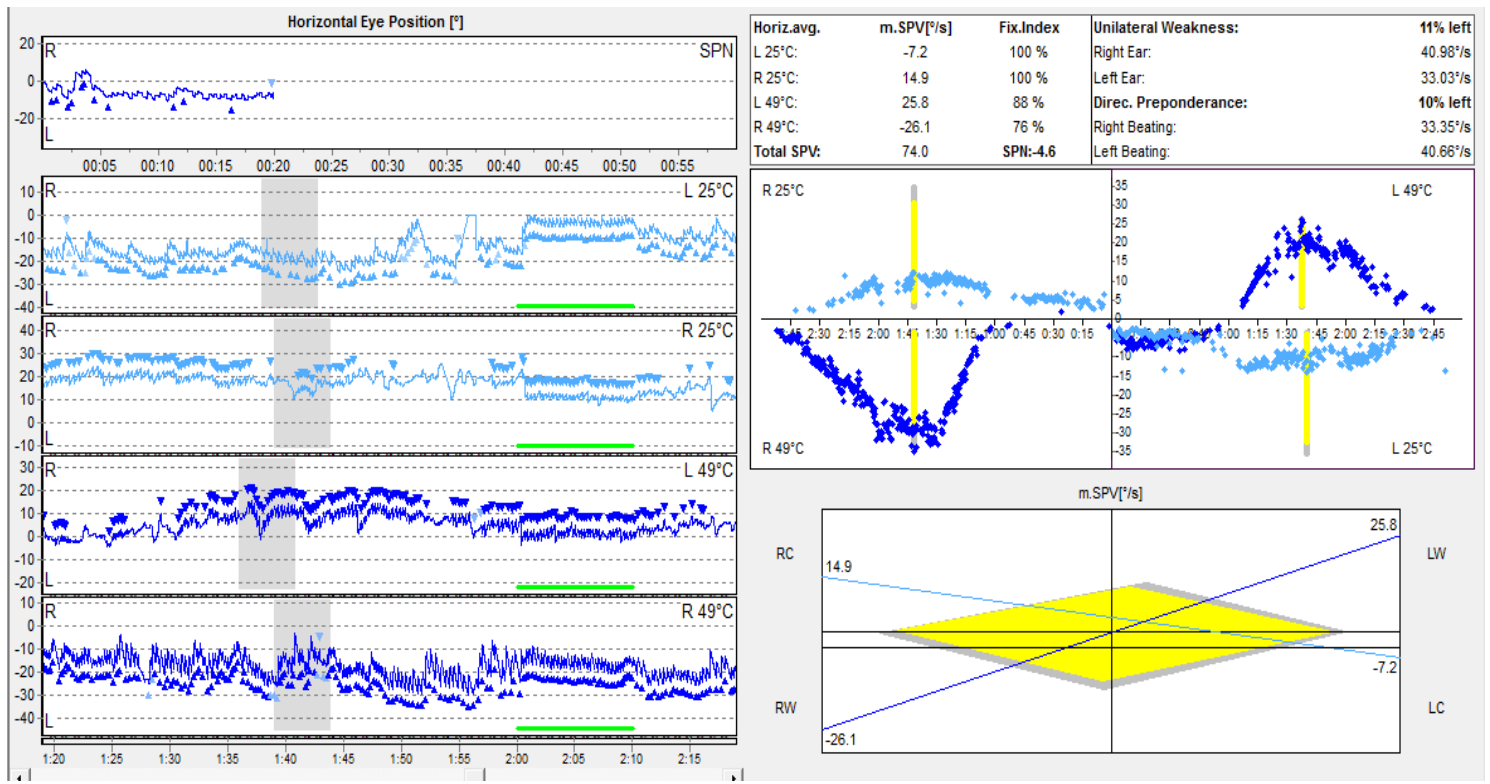

Figura 11. Inhibición defectuosa en las cuatro estimulaciones calóricas. Tiene además un nistagmo espontáneo derecho de origen central que condiciona un desplazamiento de la línea de base. 
LA PRUEBA CALÓRICA

PÉREZ-VÁZQUEZ P Y FRANCO-GUTIÉRREZ V
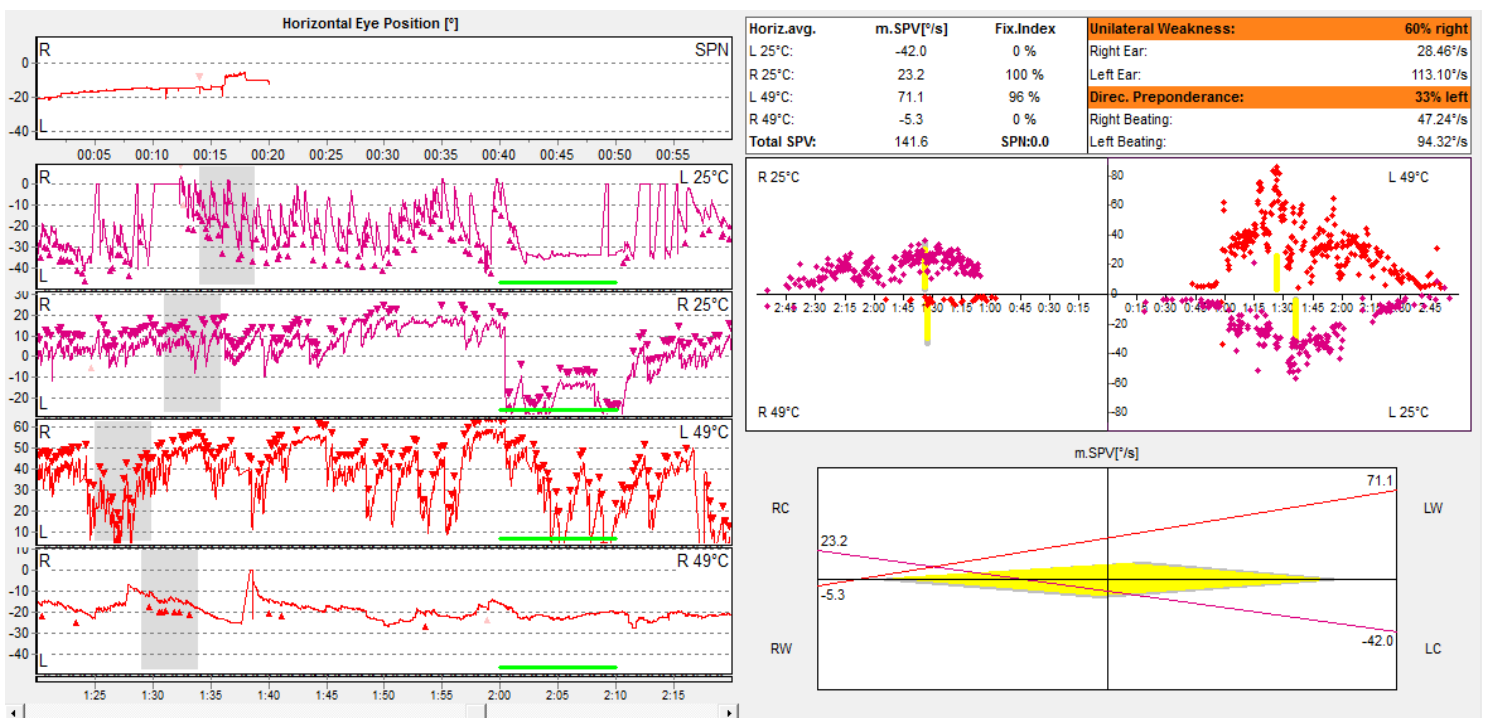

Figura 12. Prueba calórica de un paciente con patología central. Asocia a una hipovalencia derecha, una preponderancia direccional izquierda por asimetría de ganancias, una mala inhibición de las respuestas izquierdas y el aire caliente izquierdo se acerca al límite de ser considerada una respuesta hiperreactiva.
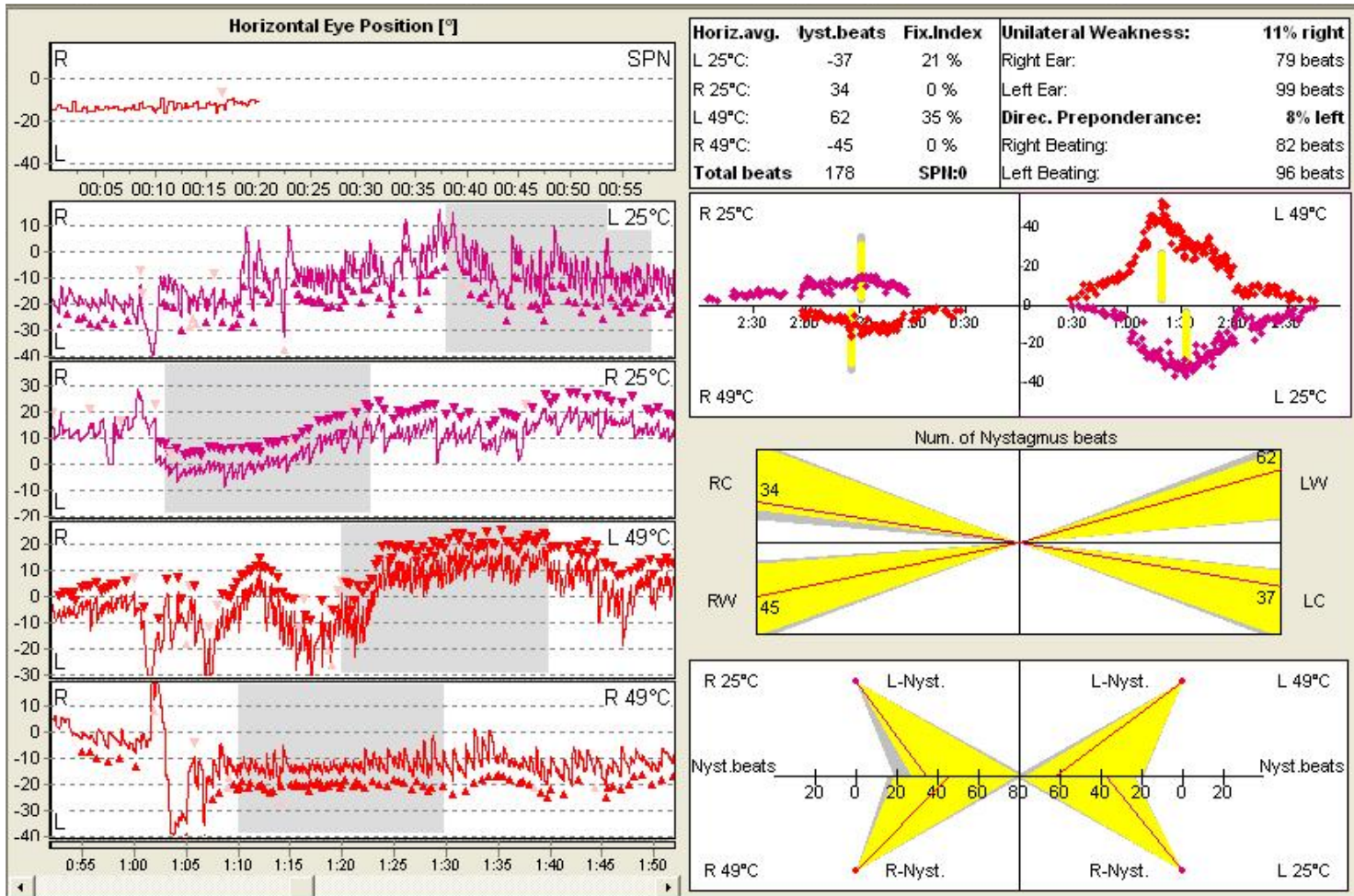

Figura 13. Prueba calórica con los resultados dados en función de la frecuencia de los nistagmos. La gráfica de velocidad/tiempo sugiere una hipofunción derecha. Sin embargo, los resultados numéricos que ofrece el programa (representados por los gráficos de Claussen y Haid-Stoll) informan una prueba calórica simétrica. 
LA PRUEBA CALÓRICA

PÉREZ-VÁZQUEZ P Y FRANCO-GUTIÉRREZ V

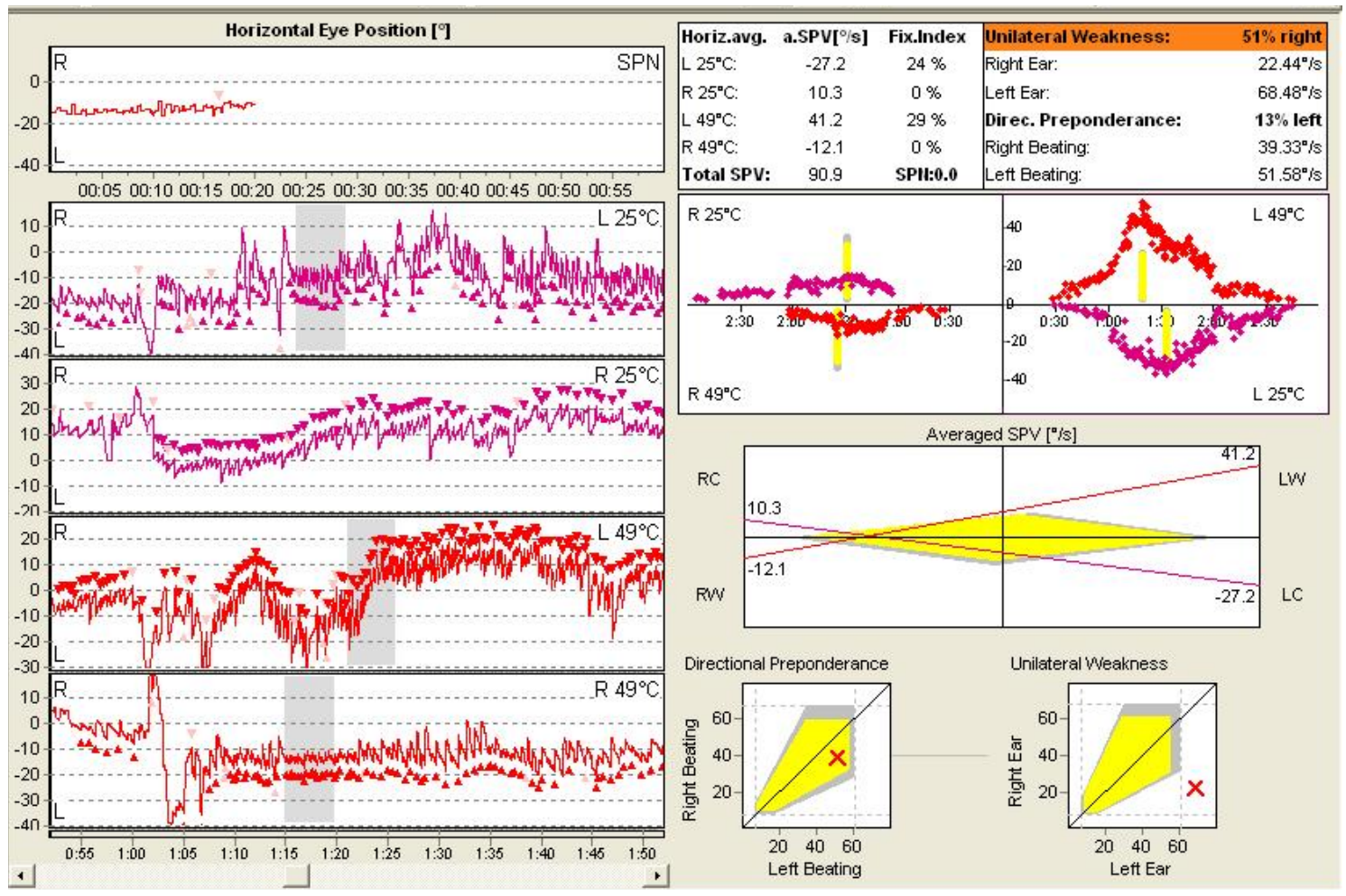

Figura 14. La misma prueba de la figura 12, analizada según la velocidad máxima de fase lenta promediada en los 5 segundos de culminación. El resultado, correcto, es una paresia canalicular derecha, como se sospechaba por el gráfico velocidad/tiempo y se muestra intuitivamente en los gráficos de Freiss y de Shenen. 
LA PRUEBA CALÓRICA

PÉREZ-VÁZQUEZ P Y FRANCO-GUTIÉRREZ V
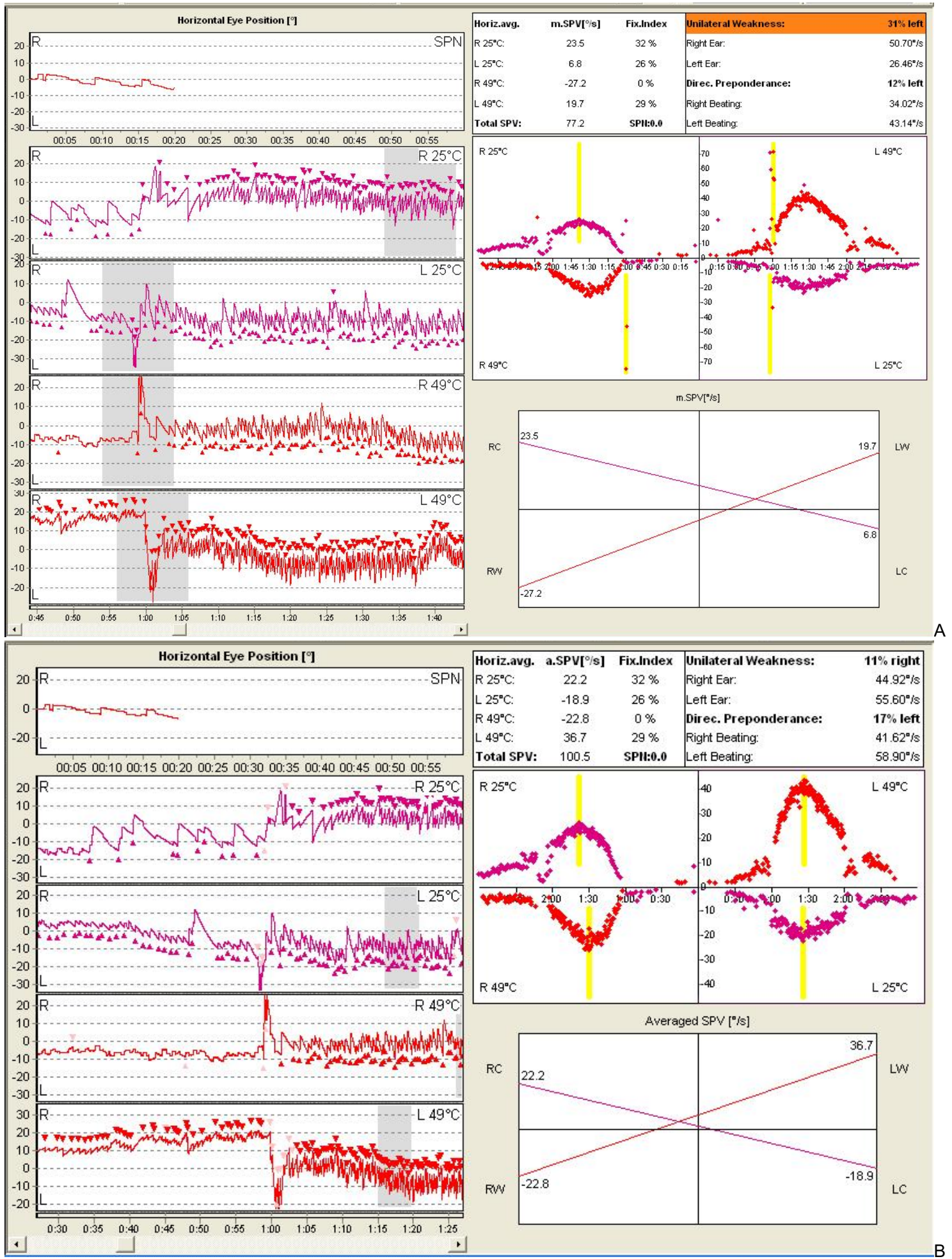

Figura 15. Artefactos. A: Prueba calórica tal y como la interpreta en primera instancia el equipo. Da un resultado de paresia canalicular izquierda, que no es concordante con el gráfico velocidad/tiempo. Como se puede apreciar, el programa ha interpretado como velocidad máxima artefactos localizados fundamentalmente en el final de las irrigaciones, cuando se reajusta la posición de la cabeza. Esto ocurre más frecuentemente cuando el programa informático se configura para señalar el nistagmo de máxima velocidad, sin promediar los adyacentes. La gráfica velocidad/tiempo parece indicar una prueba normal. B: Tras retirar los artefactos, la velocidad máxima se determina correctamente, mostrando una prueba calórica en límites normales. En este caso se da la situación de una irigación (la caliente izquierda) más intensa que las otras tres, pero que no altera el resultado final de la prueba. 